\title{
Hydrobia ulvae imposex levels at Ria de Aveiro (NW Portugal) between 1998 and 2007: a counter-current bioindicator?
}

\author{
Received 30th April 2009, Accepted 7th September 2009 \\ First published as an Advance Article on the web 13th October 2009 \\ DOI: $10.1039 / b 908597 a$
}

Susana Galante-Oliveira, ${ }^{*}$ Isabel Oliveira, Mário Pacheco and Carlos M. Barroso

Imposex expression in prosobranch gastropods has been widely used as a biomarker of tributyltin (TBT) pollution. Estuaries have been described as the most affected areas by this problem since they usually enclose the main TBT sources - ports, dockyards and marinas - resulting from the compound's application as a biocide in antifouling paints on ships. Using Hydrobia ulvae as a bioindicator, the current work addresses the most reliable methods to reduce the influence of critical variables, such as the animals' size, on imposex levels assessment for TBT pollution monitoring and presents its temporal trends from 1998 to 2007 in Ria de Aveiro (NW Portugal) to evaluate the effectiveness of recent legislation applied to reduce TBT environmental levels. H. ulvae imposex levels did not decrease in this estuarine system during the last decade despite the implementation of the EU Regulation No. $782 / 2003$. Instead, there was a global significant increase in the percentage of females affected by imposex and a slight increase of the vas deferens sequence index (VDSI), contrasting with what has been described for other bioindicators in the same study area. These results show that different biology/ecology traits determine distinct routes of TBT uptake and/or bioaccumulation, pointing the importance of choosing the bioindicator depending on the compartment that is being monitored (sediment $v s$. water). Sediment ingestion as feeding habit is discussed and pointed as a reason to choose H. ulvae as a bioindicator of TBT pollution persistence in sediment. It is therefore predicted that the response of different prosobranch species around the world may diverge according to the compartment that is being monitored and that female masculinisation may not be completely eradicated in the near future due to TBT persistence in sediments.

\section{Introduction}

Ria de Aveiro is a shallow estuarine system located in NW Portugal covering an area of $\sim 66$ to $83 \mathrm{~km}^{2}$ depending on the tide level. ${ }^{1}$ This system has a high economical potential, supporting fishing and aquaculture activities and providing conditions for the established industry, shipyard, ports and marina facilities. In addition, Ria de Aveiro is classified as a special protected area by the European Union (EU) nature and biodiversity policy 'Natura 2000 Network'. ${ }^{2}$ Hence, this is an ecosystem of considerable importance, requiring active management of its environmental quality.

CESAM \& Department of Biology, University of Aveiro, 3810-193 Aveiro, Portugal. E-mail: susana.oliveira@ua.pt; Fax: +351 234426408; Tel: +351 234370350 ext. 22752 (LEME)
Tributyltin (TBT) pollution has been monitored in Ria de Aveiro in a regular basis since 1998 in order to evaluate its ecological impact and temporal evolution in response to successive legislative actions to banish the use of this organotin (OT) compound from antifouling formulations. ${ }^{3-6}$ The first EU action was to forbid the application of organotin based antifouling paints (hereafter designated as "OT paints") on boats $<25 \mathrm{~m}$ in length through the Directive $89 / 677 /$ EEC. $^{7}$ However, this measure was ineffective in many areas where the naval traffic included larger vessels, as it was the case of Ria de Aveiro in which TBT levels remained almost unaltered for several years after the Directive's transposition in 1993., ${ }^{3,89}$ In 2001, the International Maritime Organization (IMO) adopted the 'International Convention on the Control of Harmful Antifouling Systems on Ships' (AFS Convention), ${ }^{10}$ which called for a worldwide prohibition on the OT paints application in all kind of vessels by the

\section{Environmental impact}

Tributyltin (TBT), a biocide largely applied in antifouling paints since the late $60 \mathrm{~s}$, is one of the most toxic substances ever deliberately introduced to the marine environment by mankind. One of the best documented adverse impacts of TBT in non-target organisms is imposex - the superimposition of male sexual characters in females. Legal restrictions on the use of tributyltin have been applied over the last decades till a definitive global ban in 2008. The current work points out that while some gastropods species show a decrease of imposex following the amelioration of TBT levels in the water column as a consequence of the ban, others that live and feed on sediment (e.g. Hydrobia ulvae) may not recover for many years due to long term persistence of TBT in sediment. 
effective date of 1 January 2003, and a complete banishment by 1 January 2008. However, this convention could only be applied 12 months after being ratified by 25 States, representing at least $25 \%$ of the world's merchant shipping tonnage, and so it only entered into force on 17 September 2008. ${ }^{11}$ Previewing the process delay, the EU anticipated the AFS Convention for the 1st July 2003 through the Regulation No. 782/2003. ${ }^{12}$ Therefore, it is essential to verify if this legislation is being effective to reduce TBT pollution. A well-known consequence of this pollution is imposex-the superimposition of male sexual characters onto prosobranch females ${ }^{13}$ - which has been used as a biomarker of TBT environmental concentrations. ${ }^{14-17}$ Three key indicator species have been used to monitor TBT pollution in Ria de Aveiro, namely: Nucella lapillus (L.), Nassarius reticulatus (L.) and Hydrobia ulvae (Pennant). In 1998, Barroso et al. ${ }^{3}$ recorded high levels of imposex in these species and the $N$. lapillus decreasing abundance from the system mouth inwards was attributed to the females' sterility caused by TBT. From 2003 to 2007 a decrease of imposex levels in $N$. lapillus and $N$. reticulatus has been observed in Ria de Aveiro6,18 (A. Sousa, unpublished data) as a probable consequence of the Reg. No.782/2003 implementation, and the present work intends to evaluate if the same temporal trend occurred in $H$. ulvae. This species was proposed as a TBT pollution indicator by Schulte-Oehlmann et al. ${ }^{19}$ so that the evolution of imposex levels can be used to describe the progress of TBT environmental levels. The current work establishes the most reliable methods for imposex monitoring programmes using H. ulvae, particularly those not focused previously in the literature, such as the influence of animal's size on imposex assessment. Subsequently, it addresses three key objectives: (i) the evolution of imposex in this species from 1998 to 2007 in Ria de Aveiro in order to track pollution trends; (ii) the evaluation of the legislation effectiveness to reduce TBT environmental levels; and (iii) the comparison of this temporal trend with other indicator species for the same study area.

\section{Material and methods}

The effect of animals' size on imposex parameters was studied in $H$. ulvae specimens of different shell heights $(\mathrm{SH})$ collected at St. 1 and St. 3 (Fig. 1) in February 2003, 2004 and 2007. The imposex parameters analysed were the mean female penis length $(F P L)$, the relative penis length index $[R P L I=F P L \times 100 /$ mean males penis length], the vas deferens sequence index (VDSI) and the percentage of imposex affected females $(\% \mathrm{I}) .{ }^{19}$ In the laboratory, the $\mathrm{SH}$ (distance between shell apex and the base of the aperture) was measured using a stereo microscope with a graduated eyepiece to the nearest $0.14 \mathrm{~mm}$. Shells were removed and animals were sexed. The presence of parasites was carefully checked under the stereo microscope. Although parasitized specimens were not used for the imposex monitoring surveys, as recommended by Schulte-Oehlmann et al., ${ }^{19,20}$ they were analysed separately to look for any apparent relationship between parasitism and female masculinisation. Specimens were narcotized during 60 min using $\mathrm{MgCl}_{2} 3.5 \%$ in distilled water (according to the average local salinity of around $15 \%$ ) and the penis length (PL) was measured in all animals using a stereo microscope with a graduated eyepiece to the nearest $0.06 \mathrm{~mm}$, whilst the vas deferens sequence (VDS) stage was assessed in females according to the scheme proposed by Schulte-Oehlmann et al. ${ }^{19}$ For females the FPL, VDSI and \%I were calculated per SH class $(1.50-2.75 ; 2.76-4.00 ; 4.01-5.25 ; 5.26-6.50 \mathrm{~mm})$ and analysed graphically. For males a multiple linear regression (using Statistica v6.0 software) was conducted to determine if animals' SH have a significant effect on male penis length (MPL) and if this relationship varies with sampling sites or dates.

The effect of narcotization on $H$. ulvae penis length was studied in a sample of specimens representing a wide range of $\mathrm{SH}$ collected in 2003 at St. 3 (Fig. 1). After shell removal, animals were sexed and PL was measured. Specimens were narcotized during $60 \mathrm{~min}$ using the $\mathrm{MgCl}_{2} 3.5 \%$ solution and PL was measured again. The difference between penis length measurements before $\left(\mathrm{PL}_{\mathrm{b}}\right)$ and after $(\mathrm{PL})$ narcotization was assessed by regression analysis (after checking homoscedasticity, linearity, and normally distributed error terms assumptions) and by the Wilcoxon signed-rank test.

For the purpose of assessing the evolution of H. ulvae imposex levels in Ria de Aveiro, specimens with an average $\mathrm{SH}$ around 4.0-6.0 mm were collected at St. 1-10 (Fig. 1) between November 2002 and March 2003 (here referred as '2003' survey), between April and May 2004 ('2004' survey) and in August 2007 ('2007' survey). About 60-80 individuals were collected at each site, which is well above the minimum of 30 recommended by SchulteOehlmann et $a .^{20}$ for study areas with a high imposex incidence. The imposex parameters FPL, RPLI, VDSI and \%I were determined for each sample, as described above. Statistical comparisons of SH, PL and VDS stage between the different surveys were performed for each site using the Kruskal-Wallis test followed by Dunn's post-hoc tests, taking the specimens randomly sampled along time as observations. These comparisons included also data obtained previously in 1998 by Barroso et al. ${ }^{3}$ for the same locations, using exactly the same methods as in the current study. An additional analysis was conducted for the whole study area with the Friedman test to verify if the combined females $\mathrm{SH}$, FPL, VDSI or $\%$ I of the 8 common sites (where animals were found in all sampling occasions) changed significantly over the period from 1998 (data from Barroso et al. ${ }^{3}$ ) to 2007.

\section{Results}

Imposex parameters are determined for a sample of adult animals from a given site but frequently the animals' size varies between different locations or sampling dates and therefore it is important to assess how this factor may influence imposex measurements. The observation of Fig. 2 and the multiple regression analysis reveal that male penis length depends on shell height $(t=25.84, p<0.001)$ and this relationship varies with sampling site $(t=-5.76, p<0.001)$ and sampling occasion $(t=$ $4.45, p<0.001)$. Regarding females it is also clear that FPL, VDS and $\% \mathrm{I}$ are strongly influenced by animal's size (Fig. 3). A steep increase in all parameters was registered in mud snails from St. 1 that presented $\mathrm{SH}$ between $1.5-4.0 \mathrm{~mm}$, followed by a slowdown tendency as animals increase further in size, which is expected since imposex tends to develop more rapidly as females reach sexual maturity. At St. 3 the same general trend was observed though with some oscillations. Hence, the size of $H$. ulvae selected for monitoring programmes has a major influence on the results, i.e. smaller females will cause an underestimation of FPL, 


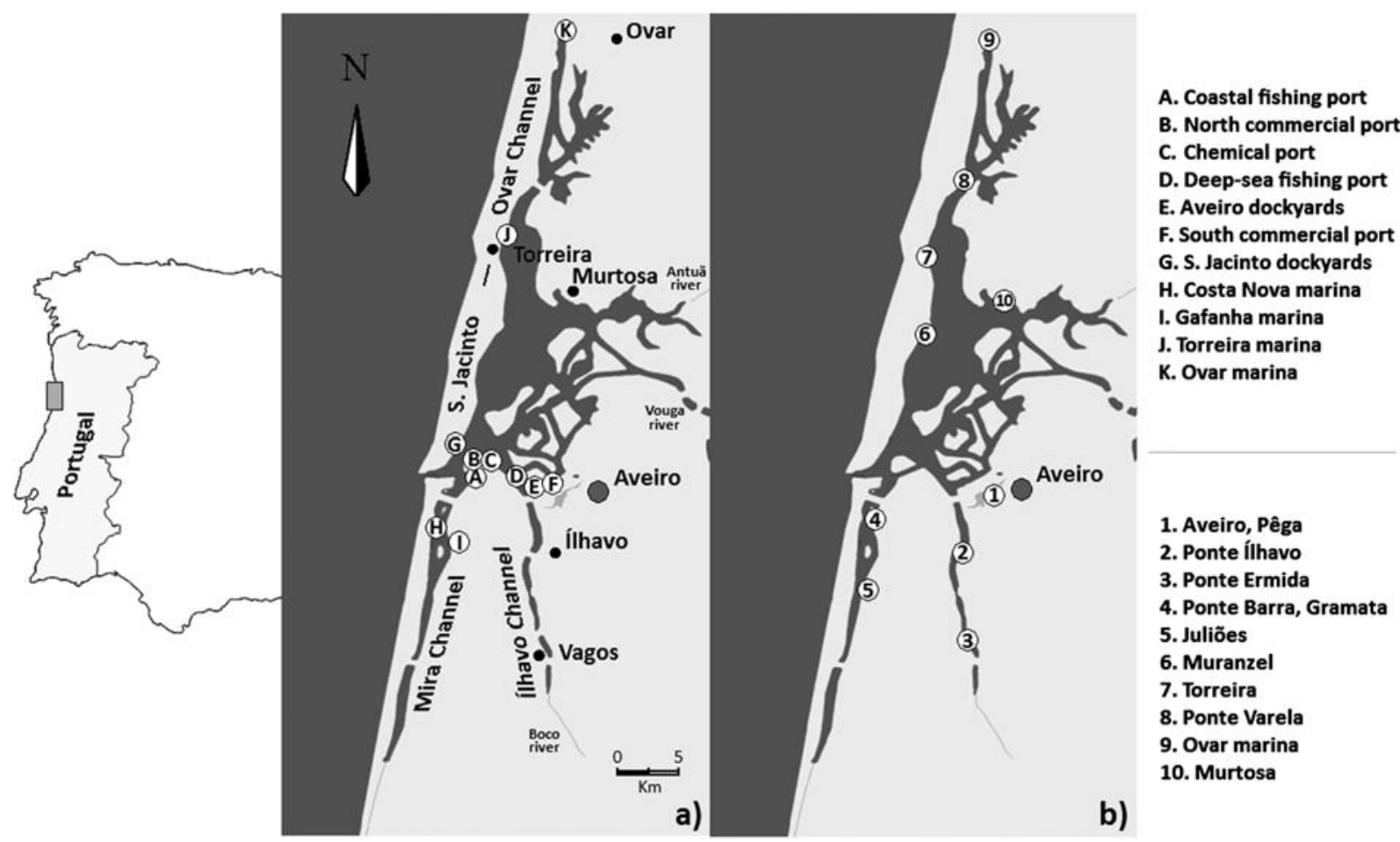

Fig. 1 Ria de Aveiro and adjacent coastal area map indicating: a) potential TBT pollution sources represented by ports, dockyards and marinas (A-K); b) sampling sites location, code and name (1-10).

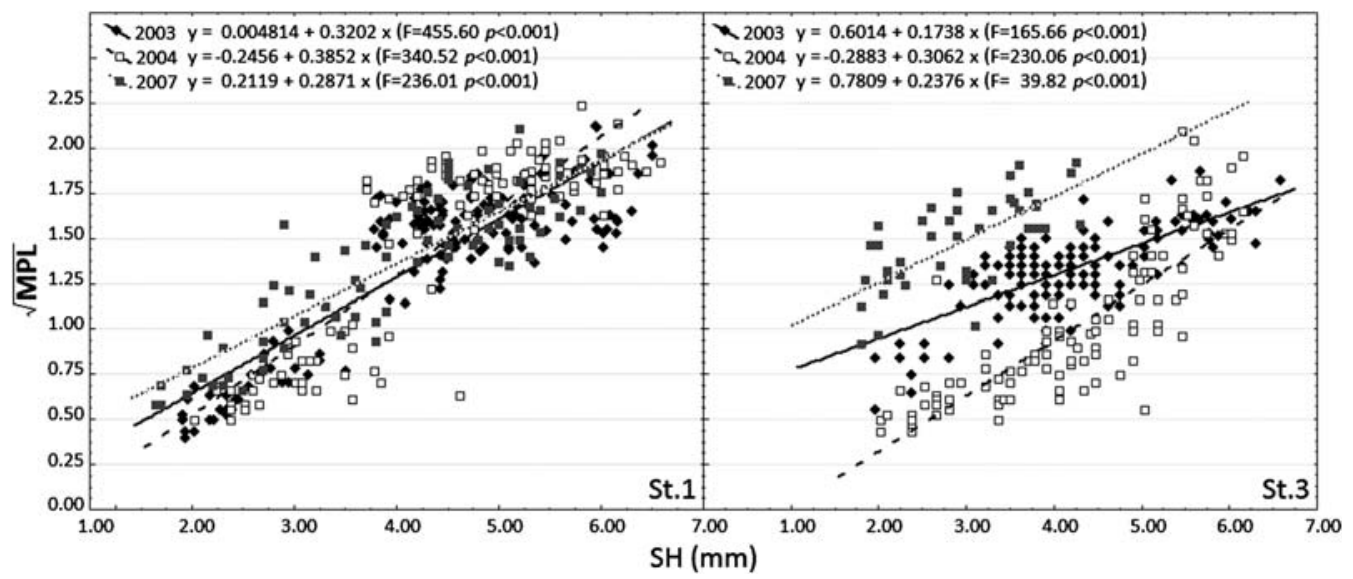

Fig. 2 Hydrobia ulvae. Relationship between male penis length (MPL) square route and shell height (SH), both expressed in millimetres (mm), at Ria de Aveiro (St. 1 and 3). For each site, three sampling occasions were compared: 2003, 2004 and 2007. Regression equations are indicated in each plot.

VDSI and \%I, whilst variation in males size cause oscillations in RPLI, regardless of TBT pollution levels.

Narcotization of mud snails facilitates animal handling and reduces penis measurement variance, since this organ ceases to contract or relax when the animal is anesthetized. However, this procedure caused an increase of the penis length in females [FPL $\left.=1.35 \mathrm{FPL}_{\mathrm{b}}-0.02 ; n=185, r^{2}=0.922 ; F=2156.10, p<0.001\right]$ and in males [MPL $=1.21 \mathrm{MPL}_{\mathrm{b}}+0.35 ; n=105, r^{2}=0.647 ; F=$ $188.65, p<0.001]$ conducing a significant difference in FPL and MPL between treatments (Wilcoxon test result for females PL: $W=853.000, p<0.001$; and for males PL: $W=5565.000, p<$ 0.001 , respectively). For this reason the comparison of imposex parameters based on this organ requires that measurements should always be performed under well standardized narcotization conditions.

H. ulvae imposex levels observed in Ria de Aveiro from 2003 to 2007 , the number of animals analysed per site and the respective mean SH are presented in Table 1. Data obtained by Barroso et al. ${ }^{3}$ from May to July 1998 are also included in this table for comparison with the current data. FPL, RPLI, VDSI and \%I varied respectively between: $0.1-0.4 \mathrm{~mm}, 6.3-20.0 \%, 0.4-1.0$ and $37.5-72.5 \%$ in $2003 ; 0.1-1.3 \mathrm{~mm}, 4.1-33.8 \%, 0.6-1.0$ and 50.0 $85.0 \%$ in $2004 ; 0.1-0.4 \mathrm{~mm}, 3.6-10.3 \%, 0.7-1.1$ and $63.4-92.5 \%$ in 2007. Sterile females were never found. It was not possible to 


\begin{tabular}{|c|c|c|c|c|c|c|c|c|}
\hline & \multicolumn{4}{|c|}{ St. 1} & \multicolumn{4}{|c|}{ St. 3} \\
\hline $\mathrm{SH}(\mathrm{mm})$ & $1.50-2.75$ & $2.76-4.00$ & $4.01-5.25$ & $5.26-6.50$ & $1.50-2.75$ & $2.76-4.00$ & $4.01-5.25$ & $5.26-6.50$ \\
\hline$n$ (2003) & 46 & 48 & 61 & 31 & 41 & 70 & 86 & 44 \\
\hline n(2004) & 14 & 22 & 32 & 27 & 9 & 25 & 43 & 36 \\
\hline n (2007) & 34 & 29 & 32 & 15 & 47 & 48 & 11 & 0 \\
\hline
\end{tabular}

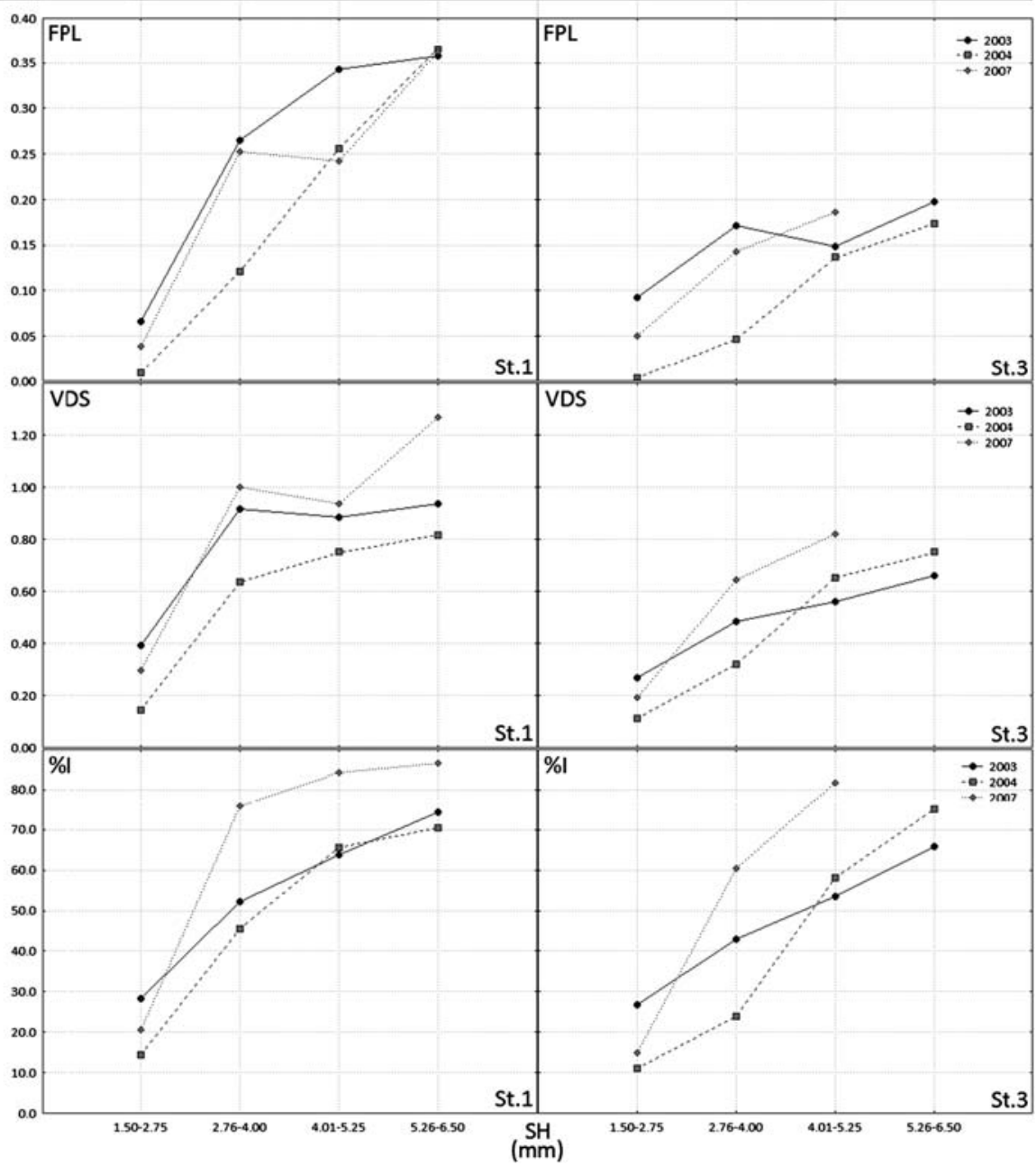

Fig. 3 Hydrobia ulvae. Variation of female penis length (FPL), vas deferens sequence (VDS) and percentage of affected females (\%I) with shell height (SH) in specimens collected at St. 1 and 3. For each site, three sampling occasions were included: 2003, 2004 and 2007. The number of specimens analysed for imposex $(n)$ per SH class $(\mathrm{mm})$ and per year is indicated on the top table.

obtain animals with uniform sizes between the different surveys neither we could observe animals as large as those found in 1998 by Barroso et al. ${ }^{3}$ (Table 1; Fig. 4). From 2003 to 2007, there was a reduction in males SH at St. 1-3, 6 and in females SH at St. 1-3 and 6-8, whilst at St. 10 both genders were larger in 2004 than in 2003 (Table 1). RPLI is a imposex parameter that roughly balance the sizes of males and females at each site ${ }^{21,22}$ but, as stated above, we found that the relationship between penis and male sizes varies throughout time at the same location, which may introduce an additional bias that is hard to control. Hence, this parameter was excluded from temporal comparisons performed in the current study. The temporal imposex evolution analysis performed for each site from 2003 to 2007 revealed that there were no significant differences in FPL and VDS for most of the sampling sites, except the cases which are described below. A significant decrease in FPL was observed at St. 2 and an increase in FPL and VDS was statistically confirmed at St. 8. However,
FPL at St. 2 in 2007 might be underestimated, as the mean females' size at that site was significantly lower in 2007. Likewise, the rising of FPL and VDSI in 2007 at St. 8 can simply result from the SH augment from 2004 to 2007 at this site. The \% w was not compared statistically under a per site analysis as there is only one reading per local; nevertheless, $\%$ I raised progressively from 2003 to 2007 at every sampling site (Table 1). Regarding the entire study area analysis no significant differences were observed in FPL from 2003 to 2007 (Friedman result: $s=1.583, p=0.531$ ) nor in VDSI from 1998 to 2007 ( $s=3.986, p=0.263)$. However, $\%$ I varied significantly during the study period $(s=16.050, p=$ 0.001 ) and post-hoc Dunn's tests revealed significant increases between 1998/2007 (Dunn's test: $s=3.292, p<0.05$ ) and 2003/ 2007 ( $s=3.292, p<0.05$ ) (Fig. 4).

Parasitized mud snails were all infected by trematodes and occurred at $10 \%, 56 \%$ and $100.0 \%$ of the sampling sites in 2003 , 2004 and 2007, respectively (Table 2). The percentage of 
Table 1 Hydrobia ulvae. Male and female mean shell heights ( $₫ \mathrm{SH}$ and $\$ \mathrm{SH})$ and the number of specimens analysed for imposex $(n)$ are presented per sampling site (St. code) and year with indication of mean male and female penis length (MPL and FPL), relative penis length index (RPLI), vas deferens sequence index (VDSI) and percentage of imposex affected females (\%I). o $\$$ SH, $\$$ SH, MPL, FPL and VDSI from 2003 to 2007 were statistically compared (indicated by brackets) and when post-hoc tests for multi-comparisons (Dunn's method) were significant, the level is indicated by asterisks- **

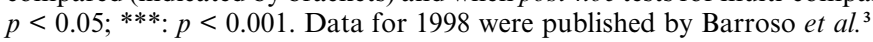

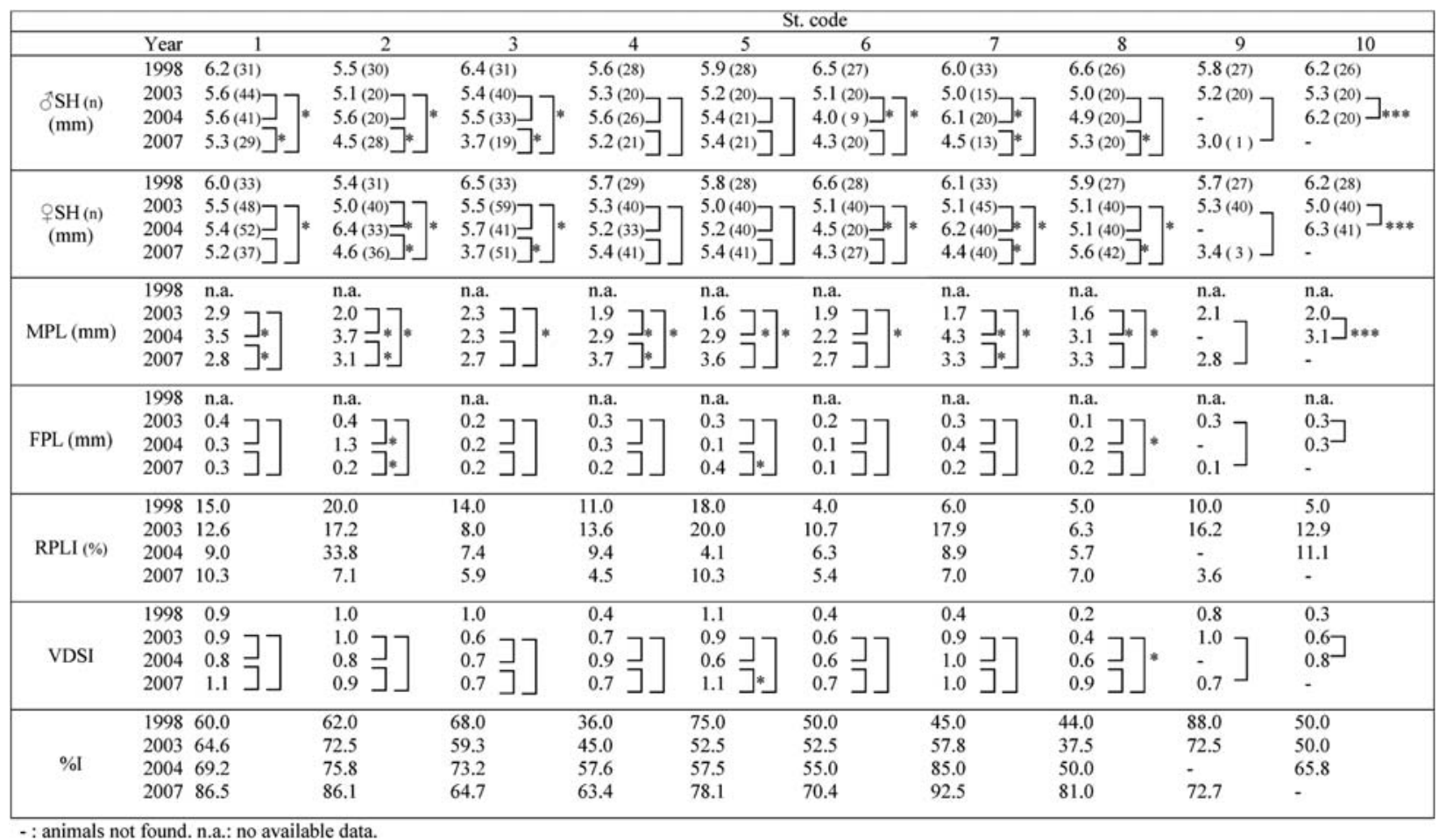

-: animals not found. n.a.: no available data.

parasitized males per site varied between $0-49 \%$ in 2004 and $0-$ $50 \%$ in 2007, whilst none was found in the 2003 survey. Infected females per site varied between $0-7 \%$ in $2003,0-60 \%$ in 2004 and $3-80 \%$ in 2007 . It is curious to note that all the parasitized females exhibited imposex and that parasitism increased over recent years as it happened with \%I. As pointed out by Schulte-Oehlmann et al. ${ }^{19}$ the investigations of Krill (1935) and Rothschild (1938) testify the occurrence of small non-functioning penes in $H$. ulvae females before TBT pollution existed, a phenomenon closely related to the infestation with trematode parasites. Nevertheless, our results disclose no significant correlation between imposex levels and the prevalence of parasitism across sites in any survey. Anyway, as already stated, we carefully examined the specimens in order to prevent that mud snails with parasites could have passed unnoticed and we excluded these animals from the imposex analysis to prevent any bias caused by this factor.

\section{Discussion}

The current study shows that imposex levels in $H$. ulvae did not decrease in Ria de Aveiro between 1998 and 2007 despite the implementation of the EU Regulation No.782/2003. Instead, for the whole study area there was a global significant increase in the percentage of females affected by imposex and a slight increase of VDSI. The mud snails' imposex evolution contrasts with what has happened with other indicator species in the same area for the identical period. In fact, a slight decrease of imposex levels in Nassarius reticulatus between 2003 and $2005^{6}$ and a highly significant decrease between 2003 and 2008 (A. Sousa, unpublished data) were observed in Ria de Aveiro. On the other hand, a significant reduction of imposex intensity in Nucella lapillus was observed after 2003 and till 2007. ${ }^{18}$ It is thus clear that different bioindicators may display different imposex temporal evolution trends. Hence, a careful discussion about the possible reasons behind these opposing trends is presented below.

Firstly, it is important to check the correctness of the imposex temporal evolution analysis conducted in the current work with mud snails. One obvious pre-requisite is that sampling campaigns from 1998 to 2007 employed identical methods. This was verified with only two exceptions. One regards the decrease in the size of specimens used in the successive surveys (Fig. 4); however, as this induces an artificial lessening of the imposex levels throughout time, imposex rising in the study area could not be caused by this factor. The other exception regards the different times of the year when surveys were conducted, but this probably did not have any effect since Silva ${ }^{23}$ observed no significant monthly variation of adult mud snails imposex levels at St. 3 between December 1999 and December 2000. One important aspect to be taken into account in imposex monitoring programmes using $H$. ulvae is the well known juvenile $(\mathrm{SH}<$ $2 \mathrm{~mm}$ ) dispersal by floating, ${ }^{24}$ which occurs in Ria de Aveiro. ${ }^{25}$ This may cause some mixing of mud snails from different TBT 
Table 2 Hydrobia ulvae. The total number $(n)$ of specimens observed in the present study (2003, 2004 and 2007 surveys) and the corresponding percentage of parasitized specimens $(\mathrm{P} \%)$ are indicated per year and sampling site (St.) for: males ( $\left.{ }^{\star}\right)$, females affected with imposex ( + VDSI $\geq 1$ ) and unaffected females ( $\%$ VDSI $=0$ )

\begin{tabular}{|c|c|c|c|c|c|c|c|}
\hline \multirow[b]{2}{*}{ St. } & \multirow[b]{2}{*}{ Year } & \multicolumn{2}{|l|}{$\sigma^{\top}$} & \multicolumn{2}{|c|}{ 은 VI $\geq 1$} & \multicolumn{2}{|c|}{$q \mathrm{VDSI}=0$} \\
\hline & & $n$ & $\mathrm{P} \%$ & $n$ & $\mathrm{P} \%$ & $n$ & $\mathrm{P} \%$ \\
\hline \multirow[t]{3}{*}{1} & 2003 & 44 & 0.0 & 28 & 7.1 & 22 & 0.0 \\
\hline & 2004 & 41 & 0.0 & 30 & 0.0 & 22 & 0.0 \\
\hline & 2007 & 29 & 0.0 & 41 & 19.5 & 4 & 0.0 \\
\hline \multirow[t]{3}{*}{2} & 2003 & 20 & 0.0 & 29 & 0.0 & 11 & 0.0 \\
\hline & 2004 & 20 & 0.0 & 25 & 0.0 & 8 & 0.0 \\
\hline & 2007 & 31 & 9.7 & 34 & 8.8 & 5 & 0.0 \\
\hline \multirow[t]{3}{*}{3} & 2003 & 40 & 0.0 & 34 & 0.0 & 25 & 0.0 \\
\hline & 2004 & 34 & 2.9 & 34 & 2.9 & 8 & 0.0 \\
\hline & 2007 & 19 & 0.0 & 36 & 5.6 & 17 & 0.0 \\
\hline \multirow[t]{3}{*}{4} & 2003 & 20 & 0.0 & 18 & 0.0 & 22 & 0.0 \\
\hline & 2004 & 51 & 49.0 & 47 & 59.6 & 14 & 0.0 \\
\hline & 2007 & 30 & 30.0 & 45 & 42.2 & 15 & 0.0 \\
\hline \multirow[t]{3}{*}{5} & 2003 & 20 & 0.0 & 21 & 0.0 & 19 & 0.0 \\
\hline & 2004 & 22 & 4.5 & 23 & 0.0 & 17 & 0.0 \\
\hline & 2007 & 29 & 27.6 & 38 & 15.8 & 9 & 0.0 \\
\hline \multirow[t]{3}{*}{6} & 2003 & 20 & 0.0 & 21 & 0.0 & 19 & 0.0 \\
\hline & 2004 & 9 & 0.0 & 11 & 0.0 & 9 & 0.0 \\
\hline & 2007 & 21 & 4.8 & 20 & 5.0 & 8 & 0.0 \\
\hline \multirow[t]{3}{*}{7} & 2003 & 15 & 0.0 & 26 & 0.0 & 19 & 0.0 \\
\hline & 2004 & 20 & 0.0 & 41 & 17.1 & 6 & 0.0 \\
\hline & 2007 & 13 & 0.0 & 42 & 4.8 & 3 & 0.0 \\
\hline \multirow[t]{3}{*}{8} & 2003 & 20 & 0.0 & 15 & 0.0 & 25 & 0.0 \\
\hline & 2004 & 20 & 0.0 & 20 & 0.0 & 20 & 0.0 \\
\hline & 2007 & 21 & 4.8 & 35 & 2.9 & 8 & 0.0 \\
\hline \multirow[t]{3}{*}{9} & 2003 & 20 & 0.0 & 29 & 0.0 & 11 & 0.0 \\
\hline & 2004 & 0 & 0.0 & 0 & 0.0 & 0 & 0.0 \\
\hline & 2007 & 2 & 50.0 & 10 & 80.0 & 1 & 0.0 \\
\hline \multirow[t]{3}{*}{10} & 2003 & 20 & 0.0 & 20 & 0.0 & 20 & 0.0 \\
\hline & 2004 & 20 & 0.0 & 37 & 27.0 & 14 & 0.0 \\
\hline & 2007 & 0 & 0.0 & 0 & 0.0 & 0 & 0.0 \\
\hline
\end{tabular}

polluted places. However, this dispersion behaviour at Ria de Aveiro seems to be confined to a very short period in the youngest stage, ${ }^{25}$ probably with negligible effect on imposex expression in older life. Besides, we minimize the possible bias caused by juveniles' mobility by using adults in the monitoring programmes and, most importantly, by assessing the evolution of imposex in the whole study area instead of focusing the analysis solely on isolated locations; either the "whole study area" or "individual site" analysis provided the same conclusion stated above: imposex in H. ulvae did not decrease over the last years, in a contrary manner to what has been recorded in the other indicator species. Another methodological aspect in biomonitoring programmes that it is important to mention is the species longevity. This is particularly important when pollution is declining as a consequence of legislative action, since imposex is largely irreversible and its reduction can only be registered when older (and most affected) specimens are substituted by younger ones. However, H. ulvae presents a short longevity (1 to 5 years) ${ }^{26,27}$ and, for Ria

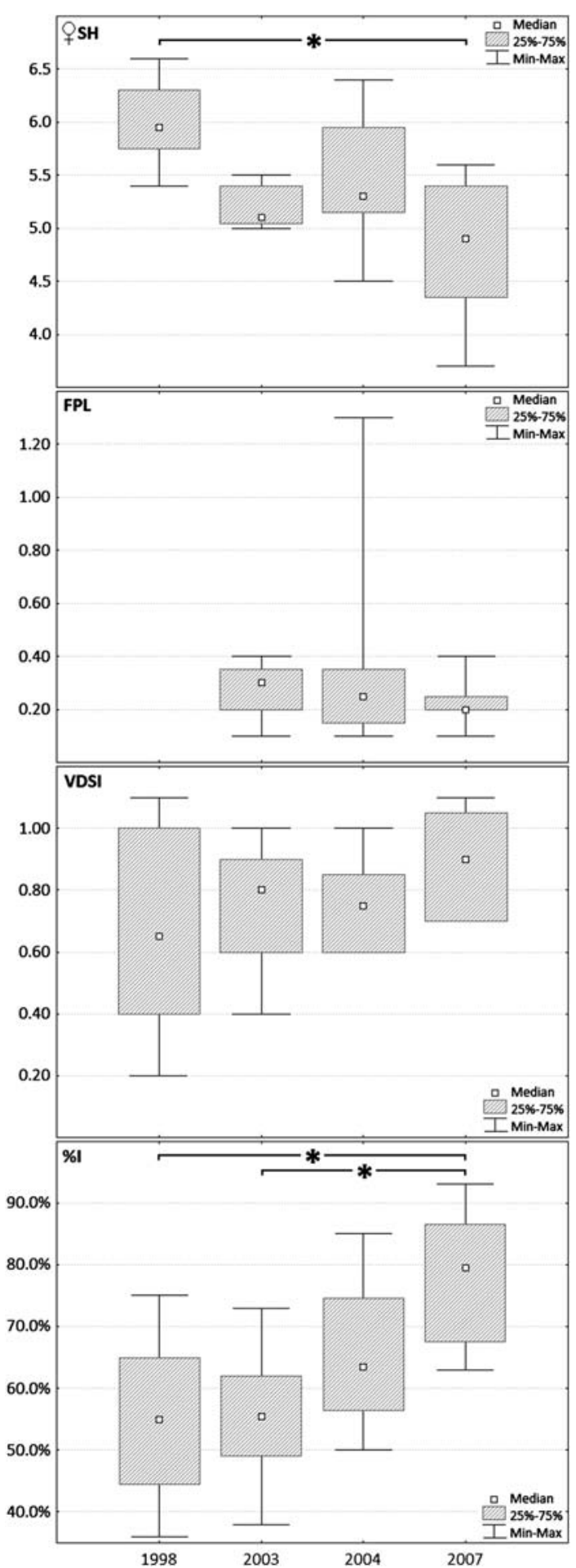

Fig. 4 Hydrobia ulvae. Global temporal trend of females' shell height (\$SH) and imposex levels (FPL, VDSI and \%I) exhibited by specimens collected at 8 common sites in Ria de Aveiro (NW Portugal): for statistical analysis St. 1-8 were pooled and the median was calculated per year-1998 (Barroso et al. ${ }^{3}$ ), 2003, 2004 and 2007 (current study).

de Aveiro, Silva ${ }^{23}$ reported longevity of around 2 years, which is very useful for monitoring short-term changes of TBT pollution. The longevity of mud snails is much lower than the reported for Nucella lapillus (5 to $>10$ years) ${ }^{28}$ and than the estimated for 
Nassarius reticulatus in the Ria de Aveiro (about 11 years), ${ }^{29}$ and so this is certainly not the cause for the discrepancy noted in the imposex evolution in the three species.

We believe from the above discussion that the distinct imposex temporal trend found in $H$. ulvae does not result from any methodological bias but rather indicates that mud snails were exposed to a different TBT pollution scenario than the other bioindicators. In fact, the different responses found between the above gastropod species in Ria de Aveiro may simply reflect different biology/ecology traits involving, for instance, distinct routes of TBT uptake and/or bioaccumulation. H. ulvae probably accumulates TBT preferentially via sediment due to its habitat and diet, as they live on sandy to muddy substrates ${ }^{30}$ and feed on diatoms and bacteria together with sediment particles, and also green algae as Ulva and Enteromorpha (Nicol, 1935 in Fretter and Graham; ${ }^{31}$ Newell, 1962 in Barnes; ${ }^{32}$ Jensen and Siegismund $^{33}$ ). It is known that $H$. ulvae processes large amounts of sediment during the feeding period: to obtain food, specimens ingest and graze contaminated particles that are then maintained in the gut during the low tide till defecation when the sediment gets re-wetted. ${ }^{34,35}$ This way, TBT uptake from the sediment and its bioaccumulation is predicted to be higher in mud snails. On the contrary, $N$. lapillus accumulates TBT preferentially via water and food (mainly mussels and barnacles which, by their turn, accumulate TBT from the water column) and so the levels of imposex in the dog-whelk predominantly indicates the level of pollution in the water. ${ }^{15,36,37}$ Similarly to $H$. ulvae, $N$. reticulatus is a sediment-dweller, adults feed on carrion and do not ingest substrate particles. This nassarid is a scavenger ${ }^{38}$ in which food was described as contributing more than half of the TBT body burden, ${ }^{36}$ minimizing the effect of the direct uptake by the contact with its internal/external body surface.

The distribution of $N$. lapillus, $N$. reticulatus and $H$. ulvae in Ria de Aveiro has to be also considered as different areas may have distinct TBT decontamination histories. The muricid and the nassarid occur in the lower estuarine zone, ${ }^{3}$ where the main port terminals are located (Fig. 1) but the area is frequently dredged and has faster currents, promoting region cleaning. ${ }^{39,40}$ $H$. ulvae extends farthest towards the upper reaches of the channels, ${ }^{3}$ shallow zones where some marinas are located and where muddy sediment retention/deposition and freshwater influence are higher. ${ }^{40}$ Thus, knowing that: (i) finer estuarine mud has higher affinity for TBT, ${ }^{41}$ (ii) TBT adsorption to the sediment is greatest in freshwater and decreases at low to intermediate salinities; and (iii) TBT desorption from the sediment is promoted by the reduction of its input in water, ${ }^{42}$ it is possible that sediment decontamination is slower in the upper reaches of the estuary. It is well-known that TBT persists adsorbed to anoxic sediment with a half-life of years, ${ }^{42-44}$ while its decay in water is much faster with half-lives of days to weeks. ${ }^{45}$ Hence, the persistence of imposex in mud snails over the last years may indicate that sediment continued to bear high levels of TBT which stills a problem in this compartment, in contrast with a rapid amelioration of the problem in water.

The European Union anticipated the adoption of the IMO AFS Convention and so it can serve as a test to evaluate the effectiveness of the legislation in reducing TBT pollution at a global scale. We can foresee that the response of the different prosobranch species around the world may diverge according to the compartment that is being monitored (sediment vs. water), and by no way we can assure that female prosobranch masculinisation will be completely eradicated in the near future as it is well known that TBT may persist in the sediment for many years.

\section{Acknowledgements}

The authors are deeply grateful to the assistance of Margarida Cardoso and Ana Sousa during sampling campaigns. This work was supported through a PhD grant to Susana Galante-Oliveira (SFRH/BD/18411/2004) attributed by the Portuguese Foundation for Science and Technology (FCT) founded by the Portuguese Government and the research project POCI/MAR/61893/ 2004 financed by the FCT and by the POCI 2010, co-financed by FEDER.

\section{References}

1 J. M. Dias, PhD Thesis, University of Aveiro, 2001.

2 C. B. Lopes, M. E. Pereira, C. Vale, A. I. Lillebø, M. A. Pardal and A. C. Duarte, Sci. Mar., 2007, 71, 293-304.

3 C. M. Barroso, M. H. Moreira and P. E. Gibbs, Mar. Ecol.: Prog. Ser., 2000, 201, 221-232.

4 C. M. Barroso, M. A. Reis-Henriques, M. Ferreira, P. E. Gibbs and M. H. Moreira, Appl. Organomet. Chem., 2005, 19, 1141-1148.

5 M. Rato, A. Sousa, R. Quintã, W. J. Langston and C. M. Barroso, Environ. Toxicol. Chem., 2006, 25, 3213-3220.

6 A. Sousa, C. Matsudaira, S. Takahashi, S. Tanabe and C. Barroso, Mar. Pollut. Bull., 2007, 54, 1645-1653.

7 EC Official Journal, Directive 89/677/EEC, Ref. No. OJ L 398, pp. 24, 1989.

8 C. M. Barroso and M. H. Moreira, Mar. Pollut. Bull., 2002, 44, 480-486.

9 M. M. Santos, C. C. Hallers-Tjabbes, A. M. Santos and N. Vieira, J. Sea Res., 2002, 48, 217-223.

10 MEPC, International Convention on the Control of Harmful AntiFouling Systems on Ships (AFS Convention), Ref. No. AFS/CONF/ 26, IMO, London, 2001.

11 IMO, Summary of Conventions as at 30th November, available from http://www.imo.org/, online, cited 10.12.07, 2007.

12 EC Official Journal, Regulation No. 782/2003, Ref. No. OJ L 115, pp. $1,2003$.

13 B. S. Smith, Proc. Malacological Soc. London, 1971, 39, 377-378.

14 G. W. Bryan, P. E. Gibbs and L. G. Hummerstone, J. Mar. Biol. Assoc. U. K., 1987, 67, 525-544.

15 G. W. Bryan, P. E. Gibbs, L. G. Hummerstone and G. R. Burt, J. Mar. Biol. Assoc. U. K., 1986, 66, 611-640.

16 Y. Morcillo and C. Porte, TrAC, Trends Anal. Chem., 1998, 17, 109-116.

17 A. Picado, M. Bebianno, M. Costa, A. Ferreira and C. Vale, Hydrobiologia, 2007, 587, 79-87.

18 S. Galante-Oliveira, I. Oliveira, N. Jonkers, M. Pacheco and C. M. Barroso, J. Environ. Monit., 2009, 11, 1405-1411.

19 U. Schulte-Oehlmann, J. Oehlmann, P. Fioroni and B. Bauer, Mar. Biol., 1997, 128, 257-266.

20 U. Schulte-Oehlmann, J. Oehlmann, B. Bauer, P. Fioroni and U. S. Leffler, Hydrobiologia, 1998, 378, 215-225.

21 P. E. Gibbs, G. W. Bryan, P. L. Pascoe and G. R. Burt, J. Mar. Biol. Assoc. U. K., 1987, 67, 507-523.

22 E. Stroben, J. Oehlmann and P. Fioroni, Mar. Biol., 1992, 113, 625-636.

23 J. G. Silva, BSc Thesis, University of Aveiro, Portugal, 2002.

24 W. Armonies, Mar. Ecol.: Prog. Ser., 1992, 83, 197-206.

25 S. Meireles and H. Queiroga, J. Mar. Biol. Assoc. U. K., 2004, 84, 761-766.

26 A. Graham, in Synopses of the British Fauna, eds. D. M. Kermack and R. S. K. Barnes, The Linnean Society of London, London, 1988, pp. 186-189.

27 J. C. Sola, J. Exp. Mar. Biol. Ecol., 1996, 205, 49-62.

28 J. H. Crothers, Field Stud., 1985, 6, 291-360. 
29 C. M. Barroso, M. H. Moreira and C. A. Richardson, J. Mar. Biol. Assoc. U. K., 2005, 85, 151-156.

30 P. G. Cardoso, A. I. Lillebø, M. A. Pardal, S. M. Ferreira and J. C. Marques, J. Exp. Mar. Biol. Ecol., 2002, 277, 173-195.

31 V. Fretter and A. Graham, in British Prosobranch Molluscs: Their functional anatomy and ecology, The Ray Society, London, 1994, pp. 707-711.

32 R. S. K. Barnes, in Studies in Biology, ed. R. S. K. Barnes, Edward Arnold (Publishers) Limited, London, 1974, vol. no. 49, pp. 28-52.

33 K. T. Jensen and H. R. Siegismund, Ophelia, 1980, 1, 193-199.

34 R. S. K. Barnes, Mar. Ecol., 2006, 27, 154-159.

35 P. Y. Pascal, C. Dupuy, P. Richard, A. G. Haubois and N. Niquil, J. Sea Res., 2008, 60, 151-156.

36 E. Stroben, J. Oehlmann and P. Fioroni, Mar. Biol., 1992, 114, 289-296.
37 G. W. Bryan, G. R. Burt, P. E. Gibbs and P. L. Pascoe, J. Mar. Biol. Assoc. U. K., 1993, 73, 913-929.

38 B. Tallmark, Mar. Ecol.: Prog. Ser., 1980, 3, 51-62.

39 C. C. Lee, C. Y. Hsieh and C. J. Tien, Chemosphere, 2006, 65, $547-559$.

40 J. F. Lopes and J. M. Dias, J. Mar. Syst., 2007, 68, 507-528.

41 P. Vogt, K. H. Riitters, M. Iwanowski, C. Estreguil, J. Kozak and P. Soille, Ecol. Indic., 2007, 7, 481-488.

42 W. J. Langston and N. D. Pope, Mar. Pollut. Bull., 1995, 31, $32-43$.

43 S. J. de Mora, Tributyltin: Case Study of an Environmental Contaminant, Cambridge University Press, Cambridge, 1996.

44 K. Saeki, A. Nabeshima, T. Kunito and Y. Oshima, Chemosphere, 2007, 68, 1114-1119.

45 R. F. Lee, OCEANS '89. Proceedings, 1989. 